\title{
Immunohistochemical study of D5 antigen (an oestrogen receptor related protein) in normal breast, benign breast disease, and mammary carcinoma in situ
}

\author{
ANNE GIRLING, M CALEFFI, R J B KING, * R R MILLIS \\ From the Clinical Oncology Unit, Imperial Cancer Research Fund, Guy's Hospital and the *Hormone \\ Biochemistry Department, Imperial Cancer Research Fund, London
}

SUMMARY Patterns of staining with a monoclonal antibody which recognises D5 antigen (a 29000 $\mathrm{kD}$ oestrogen receptor-related protein) were studied in seven normal and 76 benign breast biopsy specimens as well as in 12 cases of pure in situ mammary carcinoma. Staining in benign breast lesions was weak and heterogeneous when compared with that seen in most infiltrating carcinomas. In situ carcinomas showed an intermediate pattern of staining. The finding of only small foci of weak positivity for D5 antigen in normal and benign breast disease indicated that there are similarities between the expression of D5 antigen and the presence of oestrogen receptor protein in these tissues. A further similarity was seen with in situ carcinomas, which have been shown to have lower oestrogen receptor content than infiltrating carcinomas and a more heterogeneous staining pattern with D5 than is seen in infiltrating tumours. The importance of these findings remains to be evaluated because the precise nature of D5 antigen and its association with the oestrogen receptor molecule is not fully understood.

D5 antigen is a phosphoprotein of molecular weight $29000 \mathrm{kD}$. Although its exact physiological function is still unclear, it is closely related to the oestrogen receptor protein.' Previous immunohistochemical studies with a monoclonal antibody to this antigen have shown positivity in $70 \%$ of infiltrating mammary carcinomas. The few cases of in situ carcinoma studied so far have shown less staining. ${ }^{2}$

Expression of D5 antigen in breast carcinomas correlates with cytosol oestradiol receptor content and also with response to endocrine treatment in patients with breast cancer. ${ }^{12}$ There are little data relating to the presence of the antigen in the normal breast and in benign breast disease. Biochemical studies have all shown either absence or very low oestrogen receptor content in such tissues. ${ }^{3-9}$ It was deemed of interest to study the distribution of D5 within normal and benign breast tissue to see if it related in any way to the reported findings for oestrogen receptor content.

Using a monoclonal antibody to D5 antigen (D5 antibody) we undertook an immunohistochemical study of normal breast tissue and benign breast lesions. Several cases of pure in situ carcinoma have also been included.

Accepted for publication 28 October 1987
In selecting the patients with benign breast lesions we paid particular attention to the presence of epithelial hyperplasia as these patients are generally considered to have an increased risk of subsequently developing invasive carcinoma. ${ }^{10}$

The clinical data of all the patients were reviewed to look for any association between immunohistochemical staining and features such as age, menopausal state, parity, lactation and use of oral contraceptives.

\section{Material and methods}

Representative blocks from 83 benign breast biopsy specimens obtained from 79 patients (four patients had two biopsies) were studied. These were all patients who attended the Guy's Hospital Breast Clinic during 1985 and 1986. The biopsy specimens were not taken consecutively but were selected to include the full spectrum of changes seen in benign breast disease. The study thus included seven biopsy specimens of normal breast tissue, five of which showed secretory change (pregnant or lactating), 20 fibroadenomas, six duct papillomas, and 50 cases showing a variety of features usually included under "ffibrocystic change". These 
included cystic change with and without apocrine metaplasia, sclerosing adenosis, and epithelial hyperplasia of varying degrees. The degree of epithelial hyperplasia was described in six cases as mild, in eight as moderate, in five as severe, and in five as atypical as defined by Dupont and Page. ${ }^{10}$ A separate category of "apical snouting" was delineated, a term which was used to describe epithelium in which the cells showed cytoplasmic apical blebs on their luminal border but did not have the other cytoplasmic appearances seen in true apocrine metaplasia. Twelve cases of pure in situ carcinoma (nine in situ ductal and three in situ lobular) were selected from the file, and representative blocks chosen for study. In none of these cases was there any evidence of infiltrating carcinoma. All tissues were fixed in methacarn (methanol: chloroform: acetic acid 6:3:1) and processed routinely. Antibody D5 reacts well with methacarn fixed tissue but not with other commonly used fixatives. ${ }^{1}$

Clinical details of the patients were obtained from a review of the medical records.

\section{ANTIBODY}

Antibody D5 has been previously described in detail." Briefly, it was raised against partially purified, soluble oestradiol receptor from human myometrium. It is a monoclonal antibody of class IgGl and reacts with a phosphoprotein of molecular weight $29000 \mathrm{kD}$ that is related to the oestrogen receptor protein (molecular weight $66000 \mathrm{kD}$ ) but which can be separated from the hormone binding unit.

\section{STAINING}

Sections were dewaxed by immersion in xylene followed by absolute alcohol and $70 \%$ alcohol. After washing in phosphate buffered saline (PBS) $\mathrm{pH} \mathrm{7.6,}$ fetal calf serum was applied to the slides (at a dilution of $1 / 5$ in PBS) to prevent non-specific binding of antibody. Excess serum was removed and antibody D5 applied at a concentration of $8 \mu \mathrm{g} / \mathrm{ml}$. Sections were incubated in a humid chamber for one hour at room temperature and then washed in three changes of PBS. The second antibody (peroxidase conjugated rabbit antimouse IgG [DAKO]) was diluted to a concentration of $1 / 50$ with PBS $+3 \%$ human serum $+15 \%$ fetal calf serum, and applied for $\mathbf{4 5}$ minutes. After a further three washes in PBS sections were treated for 10 minutes with fresh diaminobenzidine hydrogen peroxide solution (1 $\mathrm{mg}$ of diaminobenzidine hydrochloride/ml of PBS containing $1 \mu \mathrm{l} 100 \mathrm{vol} \%$ hydrogen peroxide). Sections were counterstained with haematoxylin, dehydrated, and mounted.

With each batch of slides positive and negative controls were included. The positive control was an infiltrating ductal carcinoma which stained strongly and uniformly with D5. A negative control was included for each case in which PBS replaced the primary antibody, permitting evaluation of any endogenous peroxidase activity in the tissue examined. Staining was recorded as either positive or negative. Even cases in which only a very small number of cells stained were classed as positive.

\section{Results}

Biopsy specimens from 79 patients with normal tissue and benign breast disease as well as from 12 patients with carcinoma in situ were analysed. The mean age of the former group of patients was $37 \cdot 1$ years (range $16-75)$. Sixty seven were premenopausal and 12 were postmenopausal. Twenty seven were nulliparous and 52 were parous, of which 27 had breast fed their babies. Fifty three patients gave a history of using oral contraceptives and 12 were taking the pill at the time of biopsy. Accurate information concerning the day of the menstrual cycle on which biopsy was performed was not available in all cases, so this datum was not analysed. The mean age of the 12 patients with in situ carcinoma was 47.5 years (range $35-72$ ). Ten were premenopausal and parous. Only four women had

Table 1 Correlation of clinical features with pathological findings in 83 benign breast biopsy specimens* and 12 cases of in situ carcinoma

\begin{tabular}{|c|c|c|c|c|c|}
\hline & $\begin{array}{l}\text { Normal } \\
(n=7)\end{array}$ & $\begin{array}{l}\text { Fibroadenoma } \\
(n=20)\end{array}$ & $\begin{array}{l}\text { Duct papilloma } \\
(n=6)\end{array}$ & $\begin{array}{l}\text { Fibrocystic change } \\
(n=50)\end{array}$ & $\begin{array}{l}\text { Carcinoma in situ } \\
(n=12)\end{array}$ \\
\hline Mean age (years) & $34 \cdot 1$ & $26 \cdot 7$ & $48 \cdot 8$ & 41 & $47 \cdot 5$ \\
\hline \multicolumn{6}{|l|}{ Menopausal state: } \\
\hline Pre- & 6 & 20 & 4 & 41 & 10 \\
\hline Post- & 1 & 0 & 2 & 9 & 2 \\
\hline \multicolumn{6}{|l|}{ Parity: } \\
\hline Nulliparous & 3 & 15 & 1 & 9 & 2 \\
\hline Parous & 4 & 5 & 5 & 41 & 10 \\
\hline History of breast feeding & 4 & 3 & 5 & 16 & 8 \\
\hline \multicolumn{6}{|l|}{ Oral contraceptive use: } \\
\hline At any time & 4 & 15 & 4 & 33 & 4 \\
\hline At time of biopsy & 1 & 7 & 1 & 4 & 0 \\
\hline
\end{tabular}

${ }^{*}$ Four of the 79 patients had two biopsy specimens taken. 
Table 2 Results of immunoperoxidase staining with antibody D5 in 83 benign breast biopsy specimens and 12 biopsy specimens of carcinoma in situ

\begin{tabular}{lccl}
\hline Histology & Total No & No positive & $\%$ Positive \\
\hline Normal & 7 & 3 & 43 \\
Fibroadenoma & 20 & 7 & 35 \\
Duct papilloma & 6 & 5 & 83 \\
"Fibrocystic change" & 50 & 40 & 80 \\
Carcinoma in situ & 12 & 11 & 92 \\
\hline
\end{tabular}

Table 3 Results of immunoperoxidase staining with antibody D5 in different histological components within category of "fibrocystic change"

\begin{tabular}{lcc}
\hline & Total No & $\begin{array}{l}\text { No showing } \\
\text { positive staining }\end{array}$ \\
\hline Epithelial hyperplasia & 24 & $12(50 \%)$ \\
Ductal: & 6 & 0 \\
$\quad$ Mild & 8 & 6 \\
$\quad$ Moderate & 5 & 3 \\
$\quad$ Severe & 2 & 1 \\
$\quad$ Atypical & 3 & 2 \\
Atypical lobular & 21 & $21(100 \%)$ \\
Apocrine metaplasia & 12 & $12(100 \%)$ \\
Spical snouting & 6 & $3(50 \%)$ \\
\hline
\end{tabular}

Table 4 Association between immunohistochemical staining and clinical features in 79 patients with benign breast disease

\begin{tabular}{llcl}
\hline Clinical feature & D5 positive & D5 negative & Total \\
\hline Premenopausal & 41 & 26 & 67 \\
Postmenopausal & 11 & 1 & 12 \\
Nulliparous & 14 & 13 & 27 \\
Parous & 38 & 14 & 52 \\
History of breast feeding & 16 & 11 & 27 \\
$\begin{array}{l}\text { Oral contraceptive use: } \\
\quad \text { Ever }\end{array}$ & 35 & 18 & 53 \\
$\quad$ Never & 17 & 9 & 26 \\
Mean age of patients & & 32 & \\
$\quad$ (years) & 40 & $(16-53)$ & \\
Range & $(17-75)$ & & \\
\hline
\end{tabular}

used oral contraceptives in the past and none was taking them at the time of biopsy. The association between the clinical and pathological findings in both groups is shown in table 1 .

The results of immunohistochemical staining with antibody D5 are summarised in table 2. Many of the cases included in the category of "fibrocystic change" showed more than one histological feature and these details are given in table 3. Again it must be emphasised that a positive result indicates the presence of any staining; in some cases this was weak and in some very focal and confined only to a single acinus or duct. Staining was always cytoplasmic and located in the epithelial cells, usually in the luminal epithelium, but in a few cases also in the basal cells, and occasionally only within the latter. Epithelial staining with D5 was seen in 55 of $83(66 \%)$ normal and benign breast biopsy specimens. In none of the cases studied was staining as homogeneous as that in the positive control (a case of infiltrating carcinoma which stained strongly with D5) (fig 1) nor as strong as that seen in most $(70 \%)$ infiltrating carcinomas. ${ }^{\prime}$

Normal resting breast was grouped with pregnant and lactating (secretory) breast tissue as the results were essentially the same. Of the three positive cases in this group, two were secretory and one was resting. In each case staining was heterogeneous and weak. In the seven fibroadenomas which showed positive staining the pattern was as heterogeneous as in normal and secretory breast but compared with that of the previous group the intensity was stronger. In two cases positive staining was within a focus of apocrine change affecting the epithelium of the fibroadenomas.

Staining was seen in 40 of the 50 cases of "fibrocystic change" (table 2). In most cases showing epithelial

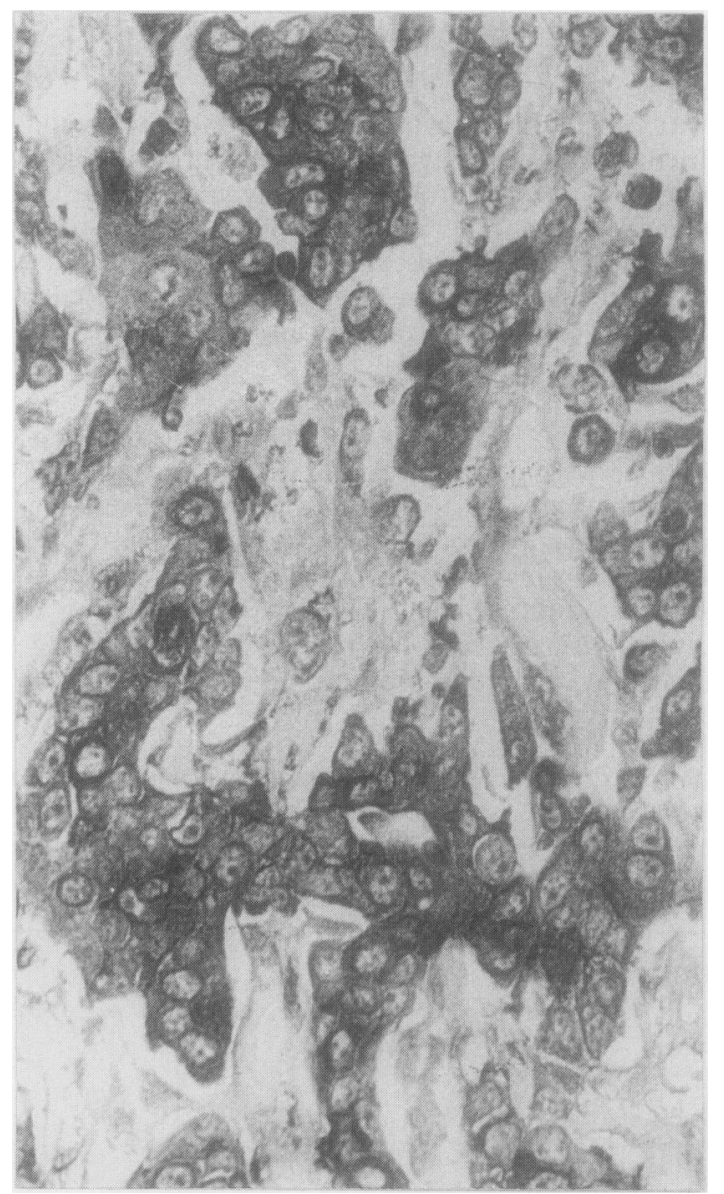

Fig 1 Infiltrating mammary carcinoma (positive control) stained with monoclonal antibody D5 (Immunoperoxidase). 
hyperplasia only a few cells in each hyperplastic area stained and there was no apparent correlation between the amount of staining and either the degree of epithelial hyperplasia or the presence of atypia. Staining was always seen in cases in which there was "apical snouting" or apocrine metaplasia (fig 2a), and it was in the latter that the strongest and most homogeneous staining of the entire group of benign breast biopsy specimens was seen. Strong and homogeneous staining was also seen in three of the six examples of sclerosing adenosis (fig 2b). Although staining was seen in five of six duct papillomas, this was usually weak, and predominantly within the basal cells. In one case the staining was within an area of squamous metaplasia.

When the clinical findings in benign biopsy specimens were related to presence or absence of staining (table 4 ) the positive biopsy specimens were seen to come from the older and parous patients but no apparent association was seen between the presence of staining and either menopausal state or use of the oral contraceptive.

In the 12 cases of pure in situ carcinoma studied 11 showed positive staining. Although the pattern was not uniform it was less heterogeneous than that described above in benign breast disease. This was particularly evident when adjacent in situ carcinoma and benign breast disease were present in the same section. Staining was never as strong and uniform as that seen in infiltrating carcinomas. Although heterogeneity was noted in every case of in situ carcinoma, in one or two cases most cells stained positively; in others only a few cells stained. There was no apparent difference between the staining of in situ

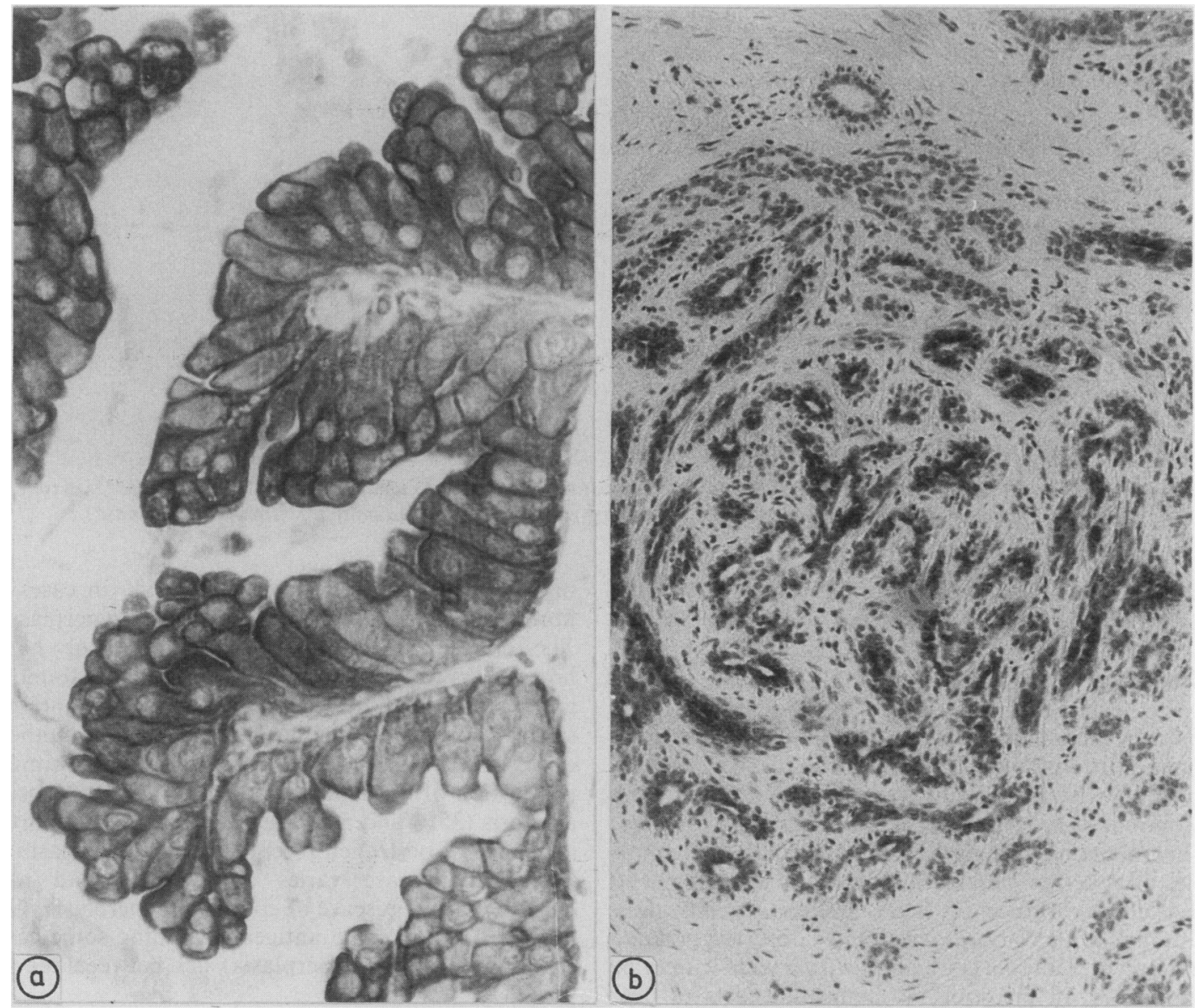

Fig 2 (a) Area of apocrine metaplasia within a case of fibrocystic change stained with monoclonal antibody D5. There is cytoplasmic staining which is strongest at luminal surface. (Immunoperoxidase.) (b) Area of sclerosing adenosis stained with monoclonal antibody D5 (Immunoperoxidase). 


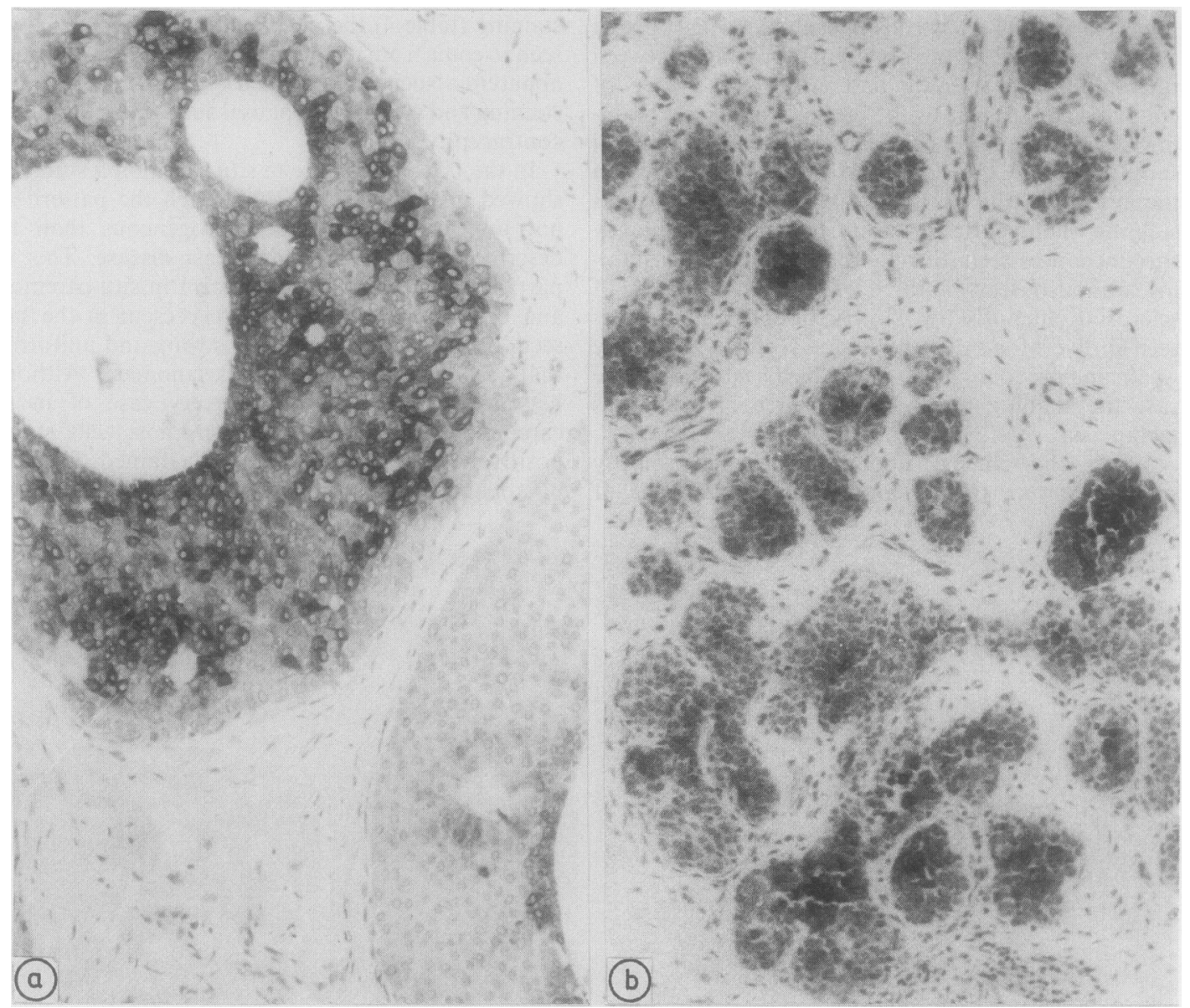

Fig 3 (a) Ductal carcinoma in situ showing heterogeneous staining with monoclonal antibody D5 (Immunoperoxidase.) (b) Lobular carcinoma in situ showing heterogeneous staining with monoclonal antibody D5 (Immunoperoxidase).

ductal and in situ lobular carcinomas, both showing an equally heterogeneous pattern (figs $3 a$ and $3 b$ ).

\section{Discussion}

Using a monoclonal antibody to D5 antigen, assessment of the amount of immunohistochemical staining in benign breast disease was difficult owing to the pronounced heterogeneity of staining seen in all cases. The only consistent finding was staining in all examples of apocrine metaplasia and apical snouting. The clinical importance of these findings is uncertain, although in this laboratory we have observed positive staining of apocrine epithelium with a wide variety of antibodies. In previous biochemical studies of oestrogen receptor status in benign breast disease, the incidence of positivity has varied from $15-55 \%$ in fibroadenomas, ${ }^{39} 50 \%$ in fibrosing adenosis, ${ }^{6} 13-33 \%$ in fibrocystic disease, ${ }^{56}$ and up to $85 \%$ in cases of fibrocystic disease showing epithelial hyperplasia. ${ }^{6}$ The concentrations of oestrogen receptor have, however, always been much lower than those found in most receptor positive carcinomas. In the present study, using an immunohistochemical method, expression of D5 antigen was found in a similar proportion of fibroadenomas and cases of sclerosing adenosis ( $35 \%$ and $50 \%$, respectively). The reported incidence of oestrogen receptor positivity in cases of fibrocystic disease varies considerably and may depend on the presence of epithelial hyperplasia. Our figure of $80 \%$ for D5 antigen (including some cases showing epithelial hyperplasia) lies between the reported extremes.

Jacquemier et al reported an incidence of $85 \%$ positivity for oestrogen receptor in cases of benign breast disease showing epithelial hyperplasia and also 
found a correlation between the degree of severity of the hyperplasia and the incidence of positivity. ${ }^{6} \mathrm{Giani}$. et al observed no such correlation. ${ }^{5}$ Looking at the expression of D5 antigen in benign breast biopsy specimens showing epithelial hyperplasia, we found an overall incidence of $50 \%$ positivity but observed no apparent association between the degree of staining and the severity of the hyperplasia. As patients whose biopsy specimens show epithelial hyperplasia are widely accepted to be at increased risk of developing subsequent carcinoma, this requires further investigation.

The clinical characteristics of patients with D5 positive biopsy specimens, differ from those reported in biochemical studies of oestrogen receptor protein. The mean age of patients with D5 positive specimens is greater than those with D5 negative ones; Allegra et al found the reverse for oestrogen receptor positivity. ${ }^{3}$ Our findings may well be explained by the fact that the older patients were more commonly those with either fibrocystic change or duct papillomas. It was within these two groups that the highest incidence of positive staining was observed (table 2). The apparent correlation with parity (which is age related) may also be explained in this way.

Our studies of the staining pattern of pure in situ carcinomas confirm the initial observations by Cano et al that less staining with D5 is seen in these lesions than in infiltrating carcinomas. ${ }^{2}$ Although staining is heterogeneous, it is more extensive than in the normal and benign breast tissues. Biochemical studies have shown lower content of oestrogen receptor protein in pure in situ carcinomas (of ductal type) than in infiltrating ductal tumours ${ }^{12}$ and there seems to be a parallel between this and expression of D5 antigen.

It thus seems that there is a gradation of expression of D5 antigen (as assessed immunohistochemically) in breast tissue with low levels of staining in normal and benign biopsy specimens, intermediate levels in carcinoma in situ, and high levels in most infiltrating carcinomas. This trend parallels that reported for oestrogen receptor protein (using biochemical methods) in these tissues. The clinical importance of these findings is uncertain at present; whether they have any clinical relevance awaits better understanding of the exact biological importance of D5 antigen, and its association with the oestrogen receptor molecule.

We thank Cheryl Gillett for her skilled technical assistance.

References

1 King RJB, Coffer AI, Gilbert J, et al. Histochemical studies with a monoclonal antibody raised against a partially purified soluble estradiol receptor preparation from human myometrium. Cancer Res 1985;45:5728-33.

2 Cano A, Coffer AI, Adatia R, Millis RR, Rubens RD, King RJB. Histochemical studies with an estrogen receptor-related protein in human breast tumours. Cancer Res 1986;46:6475-80.

3 Allegra JC, Lippman ME, Green L, et al. Estrogen receptor values in patients with benign breast disease. Cancer 1979;44:228-31.

4 Feherty P, Farrer-Brown G, Kellie AE. Oestrodiol receptors in carcinoma and benign disease of the breast: an in vitro assay. Br J Cancer 1971;25:697-710.

5 Giani C, D'Amore E, Delarue JC, et al. Estrogen and progesterone receptors in benign breast tumours and lesions: relationship with histological and cytological features. Int $J$ Cancer 1986;37:7-10.

6 Jacquemier JD, Rolland PH, Vague D, Lieutau R, Spitalier JM, Martin PM. Relationships between steroid receptor and epithelial cell proliferation in benign fibrocystic disease of the breast. Cancer 1982;49:2534-6.

7 Kuttenn F, Fournier S, Durand JC, Mauvais-Jarvis P, Baudot N, Doukani $A$. Estradiol and progesterone receptors in human breast fibroadenomas. J Clin Endocrinol Metab 1981;52:1225-9.

8 Menendez-Botet CJ, Nisselbaum JS, Fleisher M, et al. Correlation between estrogen receptor protein and carcinoembryonic antigen in normal and carcinomatous human breast tissue. Clin Chem 1976;22:1366-71.

9 Rao BR, Meyer JS, Fry CG. Most cystosarcoma phyllodes and fibroadenomas have progesterone receptor but lack estrogen receptor: stromal localization of progesterone receptor. Cancer 1981;47:2016-21.

10 Dupont WD, Page DL. Risk factors for breast cancer in women with proliferative breast disease. N Engl J Med 1985;312: 146-51.

11 Coffer AI, Lewis KM, Brockas AJ, King RJB. Monoclonal antibodies against a component related to soluble estrogen receptor. Cancer Res 1985;45:3686-93.

12 Hawkins RA, Tessdale AL, Ferguson WA, Going JJ. Oestrogen receptor activity in intraduct and invasive breast carcinomas. Breast Cancer Res Treat 1987;9:129-33.

Requests for reprints to: Dr A Girling, Research Fellow in Clinical Pathology, Clinical Oncology Unit, Imperial Cancer Research Fund, Guy's Hospital, London SE1 9RT, England. 
Notices

\section{Mucins in Histopathology}

\section{ACP Course: Wednesday, 24 May 1989 \\ Department of Pathology, University of Leeds}

Programme includes: Mucus glycoproteins-structural/functional relationships and biochemical/histochemical correlations. Critical review of histochemical techniques for the demonstration of epithelial glycoproteins. Lectins: structure, functions, and uses. Mucins in the gastrointestinal tract. Mucins in the respiratory tract. Mucins in the genitourinary tract. Mucins in the breast. Mucus antigens and cancer.

Course Fee: $£ 25.00$ (to include refreshments and lunch)

Apply to Dr M Wells, Department of Pathology, University of Leeds, Leeds LS2 9JT.

\section{National Heart and Lung Institute}

\section{Course in Lung Pathology 12-15 June 1989}

A course of lectures, hands-on microscopy sessions, and a slide seminar will be held at the National Heart and Lung Institute, Brompton Hospital, London.

Lecturers will include: B J Addis, P J Cole, B Corrin, P da Costa, B Fox, A R Gills, M Griffiths, P K Jeffery, M N Sheppard, S Stewart and C A Wagenvoort.

Programme and application forms available from: Postgraduate Centre, National Heart and Lung Institute, Dovehouse Street, London SW3 6LY. (01) 3518172.

\section{Fourth Annual Meeting Clinical Applications of Cytometry

\author{
Charleston, South Carolina, USA \\ September 13-16, 1989
}

Four symposia will cover the topics: transplantation; image analysis; quantitation of immunofluorescence and intracellular probing; and leukaemia/lymphoma immunophenotyping.

Related poster sessions and workshops will also be held.

For detailed information regarding the programme, advance registration, and submission of abstracts write to: Mariano La Via, Clinical Applications of Cytometry, P.O. Box 39778, Charleston, South Carolina 29407, USA.

\section{External Quality Assessment in Histopathology and Cytopathology}

External Quality Assessment is of increasing importance in histopathology and cytology. With the advent of the cytology proficiency testing scheme and the need to control quality of the newly implemented breast cancer screening, the Royal College of Pathologists and the Association of Clinical Pathologists are presenting a special one day symposium at St Bartholomew's Hospital, London EC1, on Monday April 24, 1989. Fee $£ 40.00$ including buffet lunch.

Further details from: Professor G Slavin, Department of Histopathology, St Bartholomew's Hospital, West Smithfield, London EC1.

\section{ACP Locum Bureau}

The Association of Clinical Pathologists runs a locum bureau for consultant pathologists.

Applicants with the MRC Path who would like to do locums and anyone requiring a locum should contact $\mathrm{Dr}$ DH Orrell, Department of Pathology, Royal Lancaster Infirmary, Ashton Road, Lancaster LA1 4RP.

\section{Corrections}

The references to the paper by Burns, Graham, and McGee were incorrect at time of press (J Clin Pathol 1988;41:897-99) and should be as follows:

\section{References}

1 Burns J, Graham AK, Frank C, Fleming KA, Evans MP, McGee JO'D. Detection of low copy human papilloma virus DNA and mRNA in routine paraffin sections of cervix by non isotopic in situ hybridization. J Clin Pathol 1987;40:858-64.

2 Syr Jonen S, Syr Jonen K. An improved in situ DHA hybridization protocol for detection of human papillomovirus (HPV) DNA sequences in paraffin-embedded biopsies. $J$ Virol Methods 1986;14:293-304.

3 Ferguson DJP, Harrison D, Burns J, Jonasson JA, McGee JO'D. Chromosomal localization of genes by scanning electron microscopy using in situ hybridization with biotinylated probes: $\mathrm{Y}$ chromosome repetitive sequences. Histochem J 1986;18:266-70.

4 Henke R-P, Milde-Lengosch K, Loning T, Kopping HS. Human papillomovirus type 13 and local epithelial hyperplasia of the oral mucosa: DNA hybridization on paraffinembedded specimens. Virchows Arch A 1987;411:193-8.

5 Chan VT-W, Fleming KA, McGee JO'D. Detection of subpicogram quantities of specific DNA sequences on blot hybridization with biotinylated probes. Nucleic Acids Res 1985;13:8083-91.

An error was inadvertently made to the title of the paper by Dr Savltzipori (J Clin Pathol 1988;41:1099-103). It should have read: Cerebral involvement associated with Escherichia coli 0157: H7 in humans and gnotobiotic piglets.

Broadsheet 120, January 1989: Folio 7 of the above broadsheet: (Guide to Diagnosis of inborn errors of metabolism in district general hospitals, has been reprinted owing to a series of printing errors (enclosed with this issue). 


\section{Correction to ACP Broadsheet 120, January 1989}

increase may be intermittent or exacerbated by a carbohydrate meal or by exercise. A chronic increase of plasma lactate concentration may be associated with increased plasma and urine alanine, plasma proline, and urate concentrations. Plasma pyruvate is usually increased but does not aid differential diagnosis.

Increased urinary lactate only occurs if the renal threshold (about $7.0 \mathrm{mmol} / \mathrm{l}$ ) is exceeded. Further investigation of a clinically important lactic acidosis includes fasting glucose, urine and plasma amino acids, and urine organic acids.

\section{AMMONIA}

Plasma ammonia in healthy adults and children (1 month to 14 years) is less than $40 \mu \mathrm{mol} / 1$ and is not affected by fasting. Healthy term infants in the first few days of life may have concentrations up to 100 $\mu \mathrm{mol} / 1$. In preterm infants and sick neonates concentrations may reach $200 \mu \mathrm{mol} / 1$. Hyperammonaemia is not a diagnosis and requires further biochemical investigation. ${ }^{14}$

\section{URINARY METHYLMALONIC ACID}

Excess urinary methylmalonic acid occurs as a result of cobalamin deficiency (including a vegan diet) or one of the several inherited defects of methylmalonic acid metabolism. The finding of methylmalonic aciduria together with homocystinuria occurs in some of the cobalamin metabolic defects. This is a complex area and the finding of methylmalonic acid in the urine must be fully investigated.

\section{URINARY SUGARS}

Clinically important galactosuria-that is, greater than $2 \mathrm{~g} / 100 \mathrm{ml}$-in a neonate suggests galactosaemia, but may also occur in patients with other causes of liver disease-for example, tyrosinaemia type I. The baby should be taken off lactose immediately while further investigations (particularly erythrocyte galactose-l-phosphate uridyl transferase and urine/plasma amino acids) are undertaken.

In older children without liver disease galactosuria suggests the possibility of galactokinase deficiency. Fructosuria requires investigation for the possibility of fructose intolerance or fructosaemia.

Beware of xylose following tolerance tests. Several minor bands - for example, lactulose, raffinose-can result from dietary sources. Heavily staining bands at or near the origin require further investigation of urinary oligosaccharides as they may indicate mucoli pidoses or possible glycogen storage disease.

More detailed interpretation of these tests and a guide to further investigations is beyond the scope of this paper, and advice from a specialist centre must be sought.

\section{Appendix}

GUIDE FOR EMERGENCY SPECIMEN COLLECTION In life-threatening situations, where an inherited metabolic disorder is thought to be likely (either from family history, results of preliminary investigations, or clinical presentation), the following specimens should be taken. At the earliest opportunity contact a specialist laboratory to discuss appropriate investigations. If possible, urine and blood specimens should be taken before death. Skin and tissue specimens should be taken as soon as possible after death.

If any of the samples are taken after death it is extremely important to record accurately both the time of death and when the samples were taken. Appropriate storage as detailed below is essential.

\section{Urine}

Ideally at least $10 \mathrm{ml}$ of random urine. Collect into a bottle with no preservative and store deep frozen $\left(-20^{\circ} \mathrm{C}\right.$ or lower). If the sample is contaminated with blood centrifuge to remove cells before freezing supernatant.

\section{Blood}

Collect $10 \mathrm{ml}$ of heparinised blood, separate plasma as soon as possible and store plasma deepfrozen $\left(-20^{\circ} \mathrm{C}\right)$. Store the packed red cells at $+4^{\circ} \mathrm{C}$ (do not freeze). If DNA analysis is likely to be required, store a further $10 \mathrm{ml}$ whole blood (edetic acid) in a plastic tube deep frozen (at least $-20^{\circ} \mathrm{C}$ ).

3 Skin (for fibroblast culture)

Skin taken up to 24 hours after death is likely to be viable provided it is not infected. Take a skin sample and place it in suitable transport medium* (obtainable from most virology or cytogenetics departments). In an emergency sterile isotonic saline can be used, but do not use agar. The specimen should be stored at $+4^{\circ} \mathrm{C}$ before despatch. Do not freeze.

Sterility is of paramount importance when taking skin biopsy specimens, especially at necropsy.

If indicated:

4 Tissue samples (liver, heart muscle, skeletal muscle) These should only be taken if there is a strong clinical suspicion of a primary defect in one of these tissues. It is very important that blood and urine specimens are also taken and not just tissue specimens. Necropsy tissue samples are only suitable for biochemical analysis if taken within two hours of death. Two or three needle biopsy specimens of tissue should be taken, wrapped in aluminium foil, and snap frozen in liquid nitrogen (or solid $\mathrm{Co}_{2}$ ). Store the sample deep frozen, as cold as possible. 